\title{
A Compound Generic Quantitative Framework for Measuring Digital Divide
}

\author{
Noureldien A. Noureldien \\ Department of Computer Science \\ University of Science and Technology, \\ Omdurman, Sudan
}

\begin{abstract}
The term digital divide had been used in the literature to conceptualize the gap in using and utilizing information and communication technologies. Digital divide can be identified on different levels such as individuals, groups, societies, organizations and countries. On the other hand, the concept of e-Inclusion is coined to define activities needed to bridge digital divide.

One of the most challenging research areas in digital divide that had been a subject for exhaustive studies is measuring digital divide. Researchers have proposed many metrics and indices to measure digital divide. However, most of the proposed measures are bivariate comparisons that reduce measurement to comparisons of Internet penetration rates or alike.
\end{abstract}

This paper proposes a compound generic framework for quantitative measuring of digital divide on the individuals or group level. The proposed framework takes into account the context of the digital divide in each society.

Keywords-Digital Divide; Digital Divide Indicator; Einclusion; Inclusion Factors; Inclusion Activities

\section{INTRODUCTION}

The term Digital Divide is coined in 1995 and popularized in the late 1990s to describe the social division among people in terms of their involvements of using information and communication technologies [1].

A widely accepted definition of digital divide is the one provided by the Organization for Economic Co-operation and Development (OECD): "the term digital divide refers to the gap between individuals, households, businesses and geographic areas at different socio-economic levels with regard both to their opportunities to access ICT and to their use of the Internet for a wide variety of activities.

The digital divide may appear due to historical, socioeconomic, geographic, educational, behavioral, or generation factors, or due to the physical incapability of individuals [2].

The underlying reasons for the increasing attention to the term are lies in the wide recognition that ICT and specifically the Internet have both empowering and discriminating ability to the citizens of a society [3].

Although the digital divide was initially understood in a binary way, that is to say, a choice between "has" and "has not" access to ICT, which is very reductive, imprecise, and inaccurate, today digital divide is understood to be a complex, multidimensional phenomenon [4][5]. The digital divide, therefore, represents "a major challenge" confronted by any information-based network society and knowledge economy.

In analyzing the digital divide phenomena, researchers took different levels of analysis. Three different levels of digital divide analysis are frequently explored, namely, global level, organizational level and individual level [6]. And in terms of the types of inequality that results from the digital divide there are at least two inter-related but conceptually different types of divide, ICT access inequality and ICT use inequality.

During last decade many voices were raised calling for the necessity of defining quantification of digital divide, that is to say, a reliable measurement and analysis of the digital divide is desperately needed.

This paper proposes a compound generic framework for quantitative measuring of digital divide based on a stated theory that correlate digital divide and e-inclusion concepts. While the author believes on the appropriateness of this approach in measuring different levels of analysis, the paper highlights only the individual or group level analysis.

The rest of this paper is organized as follows; in section 2 related research works was discussed. In section 3 the theoretical concepts and notation related to the developed framework was stated. Section 4 presents the proposed framework. Finally conclusions are given in section 5 .

\section{RELATED WORK}

The research on measuring digital divide is basically either a demonstration of the existence and magnitude of digital divide, or it focuses on the identification of various determinants of such divides. Some researchers apply statistics to quantify digital divide. In [7] the authors employ the ratio of deviation to mean as the indicator of divide magnitude. In [8] authors also took the same criterion to assess the level of national digital divide, while in [9] authors employ this approach to evaluate the magnitude of global digital divide.

It had been argued that the Gini coefficient should be especially suitable as a standard measure of digital divide [10], and it is used as standard measure to quantify the magnitude of digital divide on individual level [11]. 
Most of these approaches measure the difference in Internet Usage between individuals or social groups by using either a bivariate analysis ( such as Age less than 40 and age $>40$, Urban and rural ...etc) and use that difference as a measure for the digital divide [12][[5][13], or they use log linear modeling in order to simultaneously analyze a number of variables, called multivariate approach (such as measuring the difference in Internet usage between those who are educated and less than 16 years in Urban and rural areas, and take that difference as a measure for digital divide [14][9][15].

To overcome the problem resulted from the fact that static indicators are not sensitive to changes in the corresponding absolute magnitude of the indicator growth rates [16], the distance time methodologies are proposed as a new statistical measure in dynamic gap analysis [17]. In this new approach the levels of variable(s) are used as identifiers and time is the focus of comparison.

In [18] authors proposes three essential approaches to measure digital divide; they use loglinear modeling to address the interactions among the factors affecting the digital divide. Second, they use compound measures that integrate a number of variables into a single indicator. Third, they apply timedistance methodology to analyze changes in the digital divide.

Sometimes digital divide indicators take different or even contradictory values, to justify these indicators a compound measure can be used. Recently, various compound ICT measures have appeared, such as the Technology Achievement Index [19], the Information Society Index [20], the Internet Connectedness Index [21], Digital Access Index [3], the Networked Readiness Index [22], and the Digital Opportunity Index [23].

One of the more sophisticated examples of compound measures is the Digital Divide Index (DIDIX) which was developed within the Statistical Indicators Benchmarking Information Society (SIBIS) project, an EU research framework program led by Empirica [24].

Authors in [25] show a digital divide index DDIX, in which they have compared the technology adoption among risk groups to the adoption among the population average as a measure for the digital gap.

The proposed framework is a compound digital divide index for individual level. It is a general framework that can be applied to measure digital divide in any societal context, and it uses the e-inclusion theory to formulate a quantitative measure for digital divide.

\section{A COMPOUND GENERIC QUANTITATIVE FRAMEWORK}

This paper deals with digital divide between individuals or social groups, thus its unit of observation is individuals or social groups, and since the approach is a generic one no specific independent variables (such as age, gender, education, income, ...) or specific digital divide indicators (such as Infrastructure, Access, e-skills, Internet Usage, ....), are specified.

Only some indicators are used as examples for illustrative purposes.
The proposed measure or index will take into account the context of the digital divide in each society, that is; each society will have its own indicators and sub indicators which have weights that reflects the society context. For example, in developing countries societies, infrastructure may be defined as an indicator with high weight, while in developed countries societies that have already good infrastructure, infrastructure may not be defined as an indicator or may have a very low weight. To define the proposed quantitative framework, the following definitions and notations are introduced.

\section{Digital Divide Indicator}

A digital divide indicator defines a gap that prohibits an individual or a social group from active participation in the eSociety and can be used as a measure for defining digital exclusion. Examples of digital divide indicators are: Infrastructure, Access, Internet Usage and E-skills. The set of digital divide indicators for a given society group will be denoted by $\mathrm{Q}=\left\{\mathrm{q}_{1}, \mathrm{q}_{2}, \mathrm{q}_{3}, \ldots \mathrm{q}_{\mathrm{n}}\right\}$.

\section{Inclusion factors}

These are the societal, economical and technical factors that mitigate or eliminate the exclusion caused by a specific indicator. For example Access indicator might has the following inclusion factors: Availability of broadband, Availability of access devices (desktop, laptop, pad, phone ...etc), Affordability of Internet access prices and Basic ICT skills (editing, email, web browsing, search engines)

The set of inclusion factors for an indicator qi will be denoted by $\mathrm{Y}_{\mathrm{qi}}=\left\{\mathrm{y}_{1}, \mathrm{y}_{2}, \ldots . \mathrm{y}_{\mathrm{t}}\right\}$.

\section{Inclusion Activities}

These are activities initiated by public, private sector and civil society to provide individuals and societies with a specific inclusion factor. For example for the Access inclusion factor "Affordability of Internet access prices", the inclusion activities may include:

- providing access motivations,

- providing employment opportunities and

- providing low access prices.

The set of inclusion activities corresponding to a single inclusion factor $\mathrm{y}_{\mathrm{j}}$ will be denoted by $\mathrm{s}_{\mathrm{j}}=\left\{\mathrm{x}_{1}, \mathrm{x}_{2}, \ldots \mathrm{x}_{\mathrm{k}}\right\}$ where $\mathrm{x}_{\mathrm{m}}, 1<=\mathrm{m}<=\mathrm{k}$, is an inclusion activity.

Consequently the set of all inclusion activities corresponding to a digital divide indicator $\mathrm{q}_{\mathrm{i}}$ was denoted by $\mathrm{S}_{\mathrm{qi}}$ where $\mathrm{S}_{\mathrm{qi}}=\left\{\mathrm{s}_{1}, \mathrm{~S}_{2}, \ldots \mathrm{s}_{\mathrm{t}}\right\}$.

\section{Absolute Inclusion Factor Weight}

Inclusion factors associated with a specific indicator may have different strength and influence in mitigating digital exclusion. This strength and influence is referred to as the inclusion factor weight. The weight given to each factor should reflects the society context and should be a signed by experts. Also the assigned weight value for a given inclusion factor should consider the cost and time of the inclusion activities corresponding to that factor. 
One possible definition for such weight may be given by

$|\mathrm{yi}|=\left(\sum_{i=1}^{k}(\operatorname{Cost}(\mathrm{xi}))\right) / \mathrm{k}$

where Cost (xi) is a numerical adjusted value (0-100 for example) that mapped the financial cost and time needed to provide xi.

This inclusion factor weight will de referred to as the absolute inclusion factor weight.

Consequently, the total sum of inclusion factors absolute weights for an indicator $\mathrm{q}_{\mathrm{j}}$ is given by

$\left|\mathrm{q}_{\mathrm{j}}\right|=\sum_{i=1}^{t}|\mathrm{yi}|$

This total sum of weights assigned to inclusion factors must may be accumulated to 1 or 100 .

For example, for Access indicator the absolute inclusion factors weights might be: 40 for availability of access devices, 30 for affordability of Internet access prices and 30 for basic ICT skills.

\section{Inclusion factor gained weight}

An individual or a social group may lose or gain partially or fully an inclusion factor. For example for the inclusion factor "Affordability of Internet Access Prices" an individual may be living in urban area where broadband is available but he has a job with low income that does not allow him to afford Internet access prices.

This partially or fully losing or gaining was defined as an inclusion factor gained weight. A complete lose of an inclusion factor is evaluated to 0 weight, full gaining is evaluated to the absolute factor weight of the inclusion factor, while the weight of partially gained should be evaluated in correspondence to the inclusion activities needed to achieve the absolute weight, using the Cost function for example.

For example an individual gained weights of inclusion factors of Access Indicator might be: 40/40 for availability of access devices, 20/30 for affordability of Internet access prices and 10/30 for the basic technical ICT skills.

The gained weight values of the inclusion factor $y_{i}$ is denoted by $\left|y_{i}^{\prime}\right|$. The difference $\left(\mathrm{d}_{\mathrm{i}}\right)$, between the absolute inclusion factor weight value $\left|y_{i}\right|$, and the corresponding gained value $\left|\mathrm{y}_{\mathrm{i}}^{\prime}\right|$, is denoted by:

$$
\mathrm{d}_{\mathrm{i}}=\left|\mathrm{y}_{\mathrm{i}}-\mathrm{y}_{\mathrm{i}}^{\prime}\right|
$$

defines the gap weight of the inclusion factor $\mathrm{y}_{\mathrm{i}}$.

Consequently, the total weight of gained weigh values by an individual /social group for an Indicator $\mathrm{q}_{\mathrm{j}}$ is given by

$\left|\mathrm{q}_{\mathrm{j}}^{\prime}\right|=\sum_{i=1}^{t}\left|\mathrm{y}^{\prime} \mathrm{i}\right|$

Now, from equations (2) and (4)

$$
\left|\mathrm{q}_{\mathrm{j}}-\mathrm{q}_{\mathrm{j}}^{\prime}\right|=\sum_{i=1}^{t}\left|\mathrm{yi}-\mathrm{y}^{\prime} \mathrm{i}\right|
$$

which defines the total gap weight for a specific indicator $\mathrm{q}_{\mathrm{j}}$. Thus the total digital divide weight $|\mathrm{DD}|$ is given by

$|\mathrm{DD}|=\left(\sum_{j=1}^{n}\left|\mathrm{qj}-\mathrm{q}^{\prime} \mathrm{j}\right|\right) / \mathrm{n}$
Equation (6) gives a quantitative measure for the digital divide (DD) assuming that all indicators contribute equally to the digital divide.

If indicators contribute with different weights to $\mathrm{DD}$, for example if a digital divide DD is measured using the indicators; Infrastructure, Access, Internet Usage and E-skills, then the contribution of these indicators to the value of DD may be $40 \%, 30 \%, 15 \%$ and $15 \%$ respectively. The percentage of contribution of indicator $\mathrm{q}_{j}$ is denoted by $\alpha \mathrm{j} \%$. Consequently

$|\mathrm{DD}|=\left(\sum_{j=1}^{n}\left(\left(\left|\mathrm{qj}-\mathrm{q}^{\prime} \mathrm{j}\right| * \mathbf{\alpha j}\right) / 100\right)\right)$

\section{DisCUSSION}

The above theory shows a generic framework for quantitative measuring of digital divides. The framework relays on three levels; indicators, inclusion factors and inclusion activities.

The cost of inclusion activities plays the major role in determining the weight of its associated inclusion factor, and consequently inclusion factors weight determine the weigh their corresponding indicator contribute to whole digital divide.

\section{CONCLUSION}

Measuring digital divide is a challenging problem. Quantitative measures always have a sounding essence. This paper contributes to the theory of digital divide and proposes a generic framework for quantitative measuring of digital divide. The internal structure of the framework entails flexibility that allows considering the context of digital divide of any society and proofs its applicability in all digital divide analysis levels; global level, organizational level and individual level.

\section{REFERENCES}

[1] Hawkins, S.. Beyond the digital divide: Issues of access and economics. The Canadian Journal of Information and Library Science, 29 (2), 171189.2005.

[2] Cullen, R. Addressing the digital divide. Online Information Review 5:311-320. 2001

[3] Guillen, M. F. \& Suarez, S. L.. Explaining the global digital divide: Economic, political and sociological drivers of cross-national Internet use. Social Forces, 84(2), 681-708. 2005.

[4] Bertot, J.C., The multiple dimensions of the digital divide: more than technology 'haves' and 'haves nots', Government Information Quarterly 20, 2003, pp.185-191, 2003.

[5] Hsieh, A., Rai, A., \& Keil, MUnderstanding digital inequality: comparing continued use behavioral models of the social-economically advantaged and disadvantaged, MIS Quarterly 32, 2008, pp. 97-126.

[6] Dewan,S., Riggins, F. J.The digital divide:Current and future research directions. Journal of the Association for Information Systems, 6(12), 298-336. 2005.

[7] Cole, J. I., Suman, M., Schramm, P., Lunn, R., Aquino, J.-S., and Lebo, H. The digital future report: Surveying the digital future,year four. Ten years, ten trends. Retrieved from http://www.digitalcenter.org/downloads/DigitalFutureReport-Year42004.pdf

[8] Jin, J. \& Xiong, C. Digital divide in terms of National Information Quotient: The perspective of Mainland China. Paper presented on International Conference on The Digital Divide: Technology and Politics in the Information Age, 22-23 August 2002, Hong Kong. 
[9] Corrocher, N., Ordanini, A. Measuring the digital divide: A framework for the analysis of cross country differences. Journal of InformationTechnology, 17,9-19. 2002.

[10] Chakraborty, J. \&Bosman, M. M. Measuring the digital divide in the United States: Race, income, and personal computer ownership.The Professional Geographer, 57 (3), 395-410. 2005.

[11] Jianbin Jin \& Angus Weng Hin Cheong. Measuring Digital Divide: The Exploration in Macao, Observatorio (OBS*) Journal, 6 (2008), 259-272. 2008.

[12] Bell, P., Reddy, P. and Rainie, L. Rural Areas and the Internet. Retrieved from. http://www.pewinternet.org/pdfs/PIPRural Report.pdf,

[13] Kalkun, M., and Kalvet, T. Digital divide in Estonia and how to bridge it. Tallinn: Emor and PRAXIS Center for Policy Studies. 2002.

[14] Cava-Ferreruela, I., Alabau-Munoz, A. Key constraints and drivers for broadband development: A cross-national empirical analysis. Presented at the 15th European Regional Conference of the International Telecommunications Society (ITS), Berlin, Germany, September.2004

[15] Grigorovici, D. M., Constantin, C., Jayakar, K., Taylor, R. D., and Schement, J. R. InfoMetrics: A structural equation modeling approach to information indicators and "e-readiness" measurement. Paper presented at the 15th Biennial Conference of the International Telecommunication Society (ITS), Berlin. 2004.

[16] Sicherl, P. Different statistical measures provide different perspectives on digital divide. Paper presented at the $6^{\text {th }}$ Conference of the European
Sociological Association, Murcia.2003.

[17] Sicherl, P. A new generic statistical measure in dynamic gap analysis. The European e-Business Report. Luxembourg: European Commission. 2004.

[18] VasjaVehovar et al, Methodological Challenges of Digital Divide Measurements. The Information Society, 22: 279-290. 2006.

[19] United Nations Development Program. (2001). Human development report 2001.New York: Oxford University Press.

[20] IDC. (2001). The IDC/World Times Information Society Index: The future of the information society. Framingham, MA: IDC

[21] Jung, J.-Y., Qiu, J. L., and Kim, Y.-C. Internet connectedness and inequality: Beyond the "divide." Communication Research 28(4):507535. 2001.

[22] Dutta, S., and Jain, A. The Networked Readiness Index 2003-2004: Overview and analysis framework, 2004.

[23] International Telecommunication Union. Measuring digital opportunity. Paper presented at the WSIS Thematic Meeting on Multi-Stakeholder Partnerships for Bridging the Digital Divide, Seoul, Republic of Korea, June. 2005.

[24] Empirica, Communication and Technology Research. (2005). Retrieved from http://www.empirica.biz

[25] Tobias, H and Hannes, S. The Digital Divide Index - A measure of Social Inequalities in the Adoption of ICT, ECIS June 6-8,2002 Gdańsk, Poland. 